\title{
Undergraduate medical students' empathy: current perspectives
}

This article was published in the following Dove Press journal:

Advances in Medical Education and Practice

2 August 2016

Number of times this article has been viewed

\section{Thelma Quince \\ Pia Thiemann \\ John Benson \\ Sarah Hyde}

Primary Care Unit, Department of Public Health and Primary Care, Institute of Public Health, University of Cambridge, Cambridge, UK
Correspondence: Thelma Quince Primary Care Unit, Department of Public Health and Primary Care, Institute of Public Health, University of Cambridge, Forvie Site, Robinson Way, Cambridge CB2 OSR, UK

Tel +44I223330364

$\mathrm{Fax}+44 I 2237625 \mathrm{I}$

Email taq1000@medschl.cam.ac.uk
Abstract: Empathy is important to patient care. It enhances patients' satisfaction, comfort, self-efficacy, and trust which in turn may facilitate better diagnosis, shared decision making, and therapy adherence. Empathetic doctors experience greater job satisfaction and psychological well-being. Understanding the development of empathy of tomorrow's health care professionals is important. However, clinical empathy is poorly defined and difficult to measure, while ways to enhance it remain unclear. This review examines empathy among undergraduate medical students, focusing upon three main questions: How is empathy measured? This section discusses the problems of assessing empathy and outlines the utility of the Jefferson Scale of Empathy - Student Version and Davis's Interpersonal Reactivity Index. Both have been used widely to assess medical students' empathy. Does empathy change during undergraduate medical education? The trajectory of empathy during undergraduate medical education has been and continues to be debated. Potential reasons for contrasting results of studies are outlined. What factors may influence the development of empathy? Although the influence of sex is widely recognized, the impact of culture, psychological well-being, and aspects of undergraduate curricula are less well understood. This review identifies three interrelated issues for future research into undergraduate medical students' empathy. First, the need for greater clarity of definition, recognizing that empathy is multidimensional. Second, the need to develop meaningful ways of measuring empathy which include its component dimensions and which are relevant to patients' experiences. Medical education research has generally relied upon single, self-report instruments, which have utility across large populations but are limited. Finally, there is a need for greater methodological rigor in investigating the possible determinants of clinical empathy in medical education. Greater specificity of context and the incorporation of work from other disciplines may facilitate this.

Keywords: undergraduate medical students' empathy, Jefferson Scale of Empathy - Student Version, Davis's Interpersonal Reactivity Index

\section{Introduction}

The Francis Report into the systemic failings at the UK Mid-Staffordshire NHS Foundation Trust emphasized the importance of empathy in health care. ${ }^{1}$ Understanding what influences the empathy of tomorrow's health care professionals is as important as ensuring their clinical competence. However, clinical empathy remains poorly defined and difficult to measure, while ways to enhance it remain unclear.

Studies have shown that clinical empathy enhances patient satisfaction, comfort, and trust. ${ }^{2-5}$ Patients who trust their doctors are more likely to be open and to provide more detailed information enabling better diagnosis and shared decision making. ${ }^{6,7}$ 
Patients' belief in their own ability to cope in a specific situation (self-efficacy) may facilitate adherence to therapy. ${ }^{8,9}$ Receipt of empathy may be therapeutic in its own right. ${ }^{10-14}$

Empathetic doctors appear to experience greater job satisfaction and psychological well-being ${ }^{15}$ and have been found to make better clinical decisions ${ }^{16-19}$ and to be more effective transformational leaders. ${ }^{20}$

Despite recognition of the benefits of empathy, the concept of clinical empathy is relatively poorly defined..$^{21-23}$ This contrasts with definitions of empathy in fields such as psychology, child development, and criminology. ${ }^{24,25}$ Prior to the 1990s, there was little research into the role empathy played in effective medical care. Several writers formulated operational definitions. ${ }^{26}$ Mercer and Reynolds, ${ }^{27}$ view of clinical empathy was the ability to:

1. understand the patient's situation, perspective, and feelings (and attached meanings),

2. communicate that understanding and check its accuracy, and

3. act on that understanding with the patient in a helpful (therapeutic) way. ${ }^{27}$

This definition implies a multidimensional construct incorporating affective, cognitive, behavioral, and moral components. Neuroscience research supports the distinction between the cognitive and affective components of empathy, ${ }^{28,29}$ as do studies investigating mental disorders, child development, and criminology. ${ }^{24,30,31}$ Research into the impact of communication skills training in medical education suggests that it fosters empathetic behavior. ${ }^{32}$

Medical education research has tended to focus on the cognitive and affective dimensions of empathy, which are relatively easy to measure. Far less attention has been given to the moral dimension. Understandably, the focus has also been on measuring empathy directed toward another person. Neurological evidence suggests that parts of the brain associated with feeling pain are affected when watching someone else's pain. ${ }^{33}$ However, few studies have addressed such potentially negative effects of empathy on medical students or physicians.

This paper presents an overview of current issues relating to the study of undergraduate medical students' empathy. We focus on three main questions.

1. How is empathy measured?

2. Does empathy change during undergraduate medical education?

3. What factors may influence the development of medical students' empathy?

The paper concludes by suggesting future directions for the study of medical students' empathy.

\section{Methodology}

This paper is not a full systematic review. It draws upon extensive literature searches conducted as part of the authors' work. Searches using the terms "empathy and students" were undertaken in "PubMed" and "Scopus". For studies relating to empathy in the fields of psychology, child development, and criminology, search terms were extended to "empathy and young people". For work in psychology, we also conducted hand searches of journals noted for their publication of studies of empathy.

\section{How is empathy measured? Background}

For patients, the empathetic behavior they receive is important. However, observing the behavioral expression of empathy in the clinical setting is difficult. Asking patients to assess medical students' empathy is problematic, not least because of ethical and time issues. In addition, when patients are involved with students in an educational context, they frequently express the desire to be "helpful" and "give something back". ${ }^{34}$ Such altruistic motives undermine objective assessment. There is also the problem of what the patient perceives: is it empathy or communication style - and are the two the same? ${ }^{35}$

Assessment of medical students' empathy has tended to rely on observation by faculty, rating by standardized or simulated patients (SPs), and self-report measures. Varying degrees of agreement between these have been reported. ${ }^{36-39}$ SPs' assessments may be "socially constructed" relating to personal experiences. ${ }^{40}$ The lack of strong associations between students' scores on selfreport instruments and observations of their behavior has led some commentators to question whether students are simply "performing or faking" the behavior needed. ${ }^{41}$ This raises questions about the impact of such behavior on patients if it is devoid of sincerity. Studies in psychology have found differences between self-report measures and empathetic accuracy, that is, between what a respondent believes his/her empathetic abilities to be and how good that respondent is at rating another person's affective state. $^{42}$

Medical education research has relied strongly on self-report instruments. A review of empirical research on empathy in medicine by Hemmerdinger et al identified 36 different measures, of which 14 were self-report instruments. ${ }^{23}$ A further review of 38 instruments found that 26 did not explicitly state which dimensions of empathy were being measured. ${ }^{22}$ 


\section{Two widely used self-report instruments}

Two self-report instruments that reflect the multidimensional nature of empathy have been widely used to assess undergraduate medical students' empathy.

\section{Jefferson Scale of Empathy - Student Version}

Developed specifically to measure empathy in respect of patient care, the psychometric properties of the JSE-S have been well tested and documented. ${ }^{23,43}$ Reflecting the cognitive and affective dimensions of empathy, the Jefferson Scale of Empathy - Student Version (JSE-S) comprises 20 items relating to three underlying components: Perspective Taking (ten positively worded items), Compassionate Care (eight negatively worded items), and Standing in the Patient's Shoes (two negatively worded items). Respondents rate their level of agreement with statements on a seven-point Likert scale, higher scores indicating higher levels of agreement. The JSE-S has been extensively used with medical students and other health care profession students ${ }^{44,45}$ and with medical students in different countries. ${ }^{46-48}$

\section{Davis's Interpersonal Reactivity Index}

Davis built on his work in child development and prosocial behavior in adults to devise the Interpersonal Reactivity Index (IRI) ${ }^{49}$ The IRI comprises 28 items (19 positive, nine negative), forming four, seven-item, subscales. Davis described these as a set of related but clearly discriminable constructs, concerning responsivity to others. ${ }^{50}$

The IRI's four subscales are Perspective Taking (IRI-PT): which assesses the other person's psychological point of view, Empathetic Concern (IRI-EC): which assesses feelings and concerns for the other person, Personal Distress (IRI-PD): which measures personal feelings of anxiety and unease in tense interpersonal settings, and Fantasy Scale (IRI-FS): which assesses the tendency to transpose oneself imaginatively into the feelings and actions of fictional characters. IRI-EC and IRI-PT are "other-directed", whereas IRI-PD and IRI-FS are "self-directed". Respondents rate the extent to which statements describe themselves on a five-point Likert scale.

The use of the IRI in varying contexts provides a useful basis for comparison. It has been used to examine clinical conditions affecting social functioning and emotions, such as paranoid schizophrenia and Parkinson's disease ${ }^{51,52}$; the development of prosocial behavior among adults and adolescents ${ }^{53,54}$; the neurological basis of cognitive and affective empathy ${ }^{28}$; and the assessment of juvenile and sex offenders. ${ }^{55}$ It has also been used among US college students. ${ }^{56}$

\section{Relationship between the JSE-S and IRI scales}

The JSE-S has become the preferred instrument for assessing medical students' empathy. Work using both scales, enabling an understanding of the relationship between them, is rare. The authors have recently collaborated with colleagues in Portugal and Brazil in a study examining the underlying factor structures and relationships between the JSE-S and the IRI using data from five countries. ${ }^{57}$ This work suggests that the IRI and JSE-S are only weakly related and measure different constructs. The level of similarity of mean scores from different populations (excluding offenders) suggests that the IRI measures generic or dispositional empathy. By contrast, the JSE-S measures empathy within a health care context. As discussed later, this distinction could have important implications for both medical education and medical education research.

\section{Establishing norms}

It would be informative to understand the level of empathy that students have when beginning their course in relation to their age-related peers and similar students in other cultures. There is little comparative work, so that clear "norms" are difficult to establish. Nevertheless, after reviewing several studies, Hojat and Gonnella have suggested norms for the JSE-S. ${ }^{58}$ Table 1 presents results of recent international studies using the JSE-S in relation to these norms. Few studies report mean scores lower than the "low scorer" tentative cut-offs suggested by Hojat and Gonnella of $\leq 95$ for men and $\leq 100$ for women. ${ }^{58}$

The IRI enables comparison of medical students with other populations, since Davis's suggested norms were based on general population studies. Although the use of the IRI among medical students is less widespread, results from recent studies of medical students, comparable nonmedical students, and offenders are presented together with Davis's norms in Table 2. Few studies of medical students report mean scores for either the IRI-EC or IRI-PT below Davis's norms (Table 2). Evidence from psychology and criminology suggests that, unsurprisingly, some people with particularly low levels of empathy may display behaviors that would be inappropriate for a caring profession..$^{53,54,59}$

\section{Summary}

The measurement of medical students' empathy has relied heavily on the use of self-report instruments; the two most widely used being the JSE-S and IRI. Although they have the utility of being easily administered to large numbers of students, the extent to which they measure empathetic 
Table I Results of a sample of recent studies of medical students' empathy using the JSE-S in different countries ${ }^{\mathrm{a}}$

\begin{tabular}{|c|c|c|c|c|c|}
\hline \multirow[t]{2}{*}{ Location and reference } & \multirow{2}{*}{$\begin{array}{l}\text { Size: total } / \mathrm{male} / \\
\text { female }\end{array}$} & \multirow[t]{2}{*}{ Type of Study } & \multicolumn{3}{|c|}{ JSE-S total scores, mean (SD) } \\
\hline & & & Male & Female & Total \\
\hline USA $^{58 ;}$; suggested JSE-S norms & $\mathrm{n}=2,637 / 1,301 / 1,336$ & Various & II $2.3(10.8)$ & II $6.2(9.7)$ & II $4.3(10.4)$ \\
\hline Suggested low scorer cutoffs & & & $\leq 95.0$ & 100.0 & \\
\hline \multirow[t]{6}{*}{ India ${ }^{46}$} & $n=488 / 380 / 108$ & Cross-sectional & $101.9(19.9)$ & $106.5(16.16)$ & Semester I I07.85 (20.05) \\
\hline & & Semesters I, 3, 5, 7 and 9 & & & Semester 3100.52 (19.96) \\
\hline & & & & & Semester 5 I02.76 (20.0I) \\
\hline & & & & & Semester $797.73(16.03)$ \\
\hline & & & & & Semester 9 102.91 (17.03) \\
\hline & & & & & Average 102.9I (19.21) \\
\hline \multirow[t]{5}{*}{ Caribbean ${ }^{65}$} & $669 / 231 / 438$ & Cross-sectional & $104.3(11.78)^{\mathrm{a}}$ & $106.9(11.59)^{\mathrm{a}}$ & Year I I08.09 (II.25) \\
\hline & & Years I to 5 & & & Year $2106.69(11.00)$ \\
\hline & & & & & Year 3 I02.4I (I2.36) \\
\hline & & & & & Year 4 I05.34 (I2.4I) \\
\hline & & & & & Year 5 I04.60 (II.7I) \\
\hline \multirow[t]{2}{*}{$\operatorname{Iran}^{47}$} & Preclinical $n=423^{b}$ & Cross-sectional & & & Preclinical I05.5 (I3.2) \\
\hline & Clinical $n=47 I^{b}$ & Preclinical- Clinical & & & Clinical $99.7(14.6)$ \\
\hline \multirow[t]{2}{*}{ Portugal ${ }^{66}$} & $n=476 /|55 / 32|$ & Cross-sectional & $110.32(10.69)$ & $\mathrm{II} 2.86(\mid 0.8 \mathrm{I})$ & Year I II 0.31 ( 10.63$)$ \\
\hline & & Years I and 6 & & & Year 6 II $8.21(9.10)$ \\
\hline \multirow[t]{2}{*}{ Australia $^{120}$} & $n=404 / 175 / 229$ & Cross-sectional & $106.15^{c}$ & $111.30^{c}$ & $109.07(14.93)^{\mathrm{a}}$ \\
\hline & & Years I and 5 & & & \\
\hline \multirow[t]{4}{*}{ Korea $^{48}$} & $n=5,343 / 3,287 / 2,056$ & Cross-sectional & $105.25(13.37)$ & $106.95(11.74)$ & Year I I06.4 I (I2.39) \\
\hline & & Years I to 4 & & & Year 2 I06.77 (12.28) \\
\hline & & & & & Year 3105.18 (12.59) \\
\hline & & & & & Year 4 I04.97 (14.04) \\
\hline \multirow[t]{2}{*}{$J^{J a p a n}{ }^{68}$} & $n=400 / 275 / 103$ & Cross-sectional & $103.7(13.2)$ & $107.0(11.1)$ & $104.3(13.1)^{\mathrm{a}}$ \\
\hline & & Years I to 6 & & & \\
\hline \multirow[t]{2}{*}{$\mathrm{UK}^{85}$} & $n=2,059 / 796 / 1263$ & Cross-sectional & I I 0.04 (I I.57) & II 3.87 (I0.32) & Year I II2.53 (I0.45) \\
\hline & & Years $I$ and 5 or $6^{d}$ & & & Year 5 or 6 II 2.37 (II.75) \\
\hline \multirow[t]{2}{*}{ New Zealand ${ }^{85}$} & $n=305 / 119 / 186$ & Cross-sectional & II2.5I (II.35) & I I 8.20 (9.87) & Year I/2 II6.35 (9.80) \\
\hline & & Years $1 / 2$ and $5^{e}$ & & & Year 5 II 5.55 (II.93) \\
\hline \multirow[t]{2}{*}{ Ireland ${ }^{85}$} & $\mathrm{n}=1 / 10 / 37 / 73$ & Cross-sectional & $111.38(10.16)$ & 114.18 (9.19) & II $3.24(9.57)^{\mathrm{a}}$ \\
\hline & & Years I and 6 & & & \\
\hline
\end{tabular}

Notes: anless average scores for each year or semester are given, the figures in the table relate to average total scores for all years. ${ }^{b} \mathrm{No}$ data for males and females reported separately. 'No standard deviation figures given by sex. ${ }^{\mathrm{d}}$ Comparison of Year I and final year students in I 5 UK medical schools which varied in respect of whether course was 5 or 6 years in duration. ${ }^{\mathrm{A}} \mathrm{A}$ proportion of the students had completed a common foundation course in healthcare prior to commencing medical education leading to a doctor qualification. Data from Hojat and Gonnella. ${ }^{58}$ Adapted from: Shashikumar R, Chaudhary R, Ryali VS, et al. Cross sectional assessment of empathy among undergraduates from a medical college. Med J Armed Forces India. 2014;70(2):I79-185. Copyright (C) 2014 Published by Elsevier B.V. on behalf of Director General, Armed Forces Medical Services. ${ }^{46}$ Shariat SV, Habibi M. Empathy in Iranian medical students: measurement model of the Jefferson Scale of Empathy. Med Teach. 20I3; 35(I):e9I3-e9I8. Copyright (C) 2013 Taylor \& Francis Ltd. Reprinted by permission of the publisher (Taylor \& Francis Ltd; http://www.tandfonline.com). ${ }^{47}$ Park KH, Roh H, Sun DH, Hojat M. Empathy in Korean medical students: findings from a nationwide survey. Med Teach. 2015;37(10): 943-948. ${ }^{48}$ Youssef FF, Nunes P, Sa B, Williams S. An exploration of changes in cognitive and emotional empathy among medical students in the Caribbean. Int J Med Educ. 20I4;5:185-192.65 Magalhães E, Salgueira AP, Costa P, Costa MJ. Empathy in senior year and first year medical students: a cross-sectional study. BMC Med Educ. 20I I; I I:52. ${ }^{66}$ Kakaoka HU, Koide N, Ochi K, Hojat M, Gonnella JS. Measurement of empathy among Japanese medical students: psychometrics and score differences by gender and level of medical education. Acad Med. 2009;84(9):II92-1197. Copyright (C) 2009 Wolters Kluwer Health. Promotional and commercial use of the material in print, digital or mobile device format is prohibited without the permission for the publisher Wolters Kluwer Health. Please contact healthpermissions@wolterskluwer.com for further information. ${ }^{68}$ Quince TA, Kinnersley P, Hales J, et al. Empathy among undergraduate medical students: A multi-centre cross-sectional comparison of students beginning and approaching the end of their course. BMC Med Educ. 20I6; I6(I):92. ${ }^{85} \mathrm{Hegazi}$ I, Wilson I. Maintaining empathy in medical school: it is possible. Med Teach. 2013;35(I2):1002-1008. Copyright @ 2013 Taylor \& Francis Ltd. Reprinted by permission of the publisher (Taylor \& Francis Ltd; http://www.tandfonline.com). ${ }^{120}$

Abbreviations: JSE-S, Jefferson Scale of Physician Empathy- Student Version; SD, standard deviation.

behavior is questionable. Recent evidence suggests that the JSE-S and IRI are weakly related and measure different constructs. However, the establishment of "norms" for both instruments can facilitate comparison of medical students and the extent to which medical students differ from their age-related peers.

\section{Does empathy change during undergraduate medical education?}

Longitudinal and cross-sectional studies undertaken early in this century suggested that empathy declined during undergraduate medical education. ${ }^{60-62}$ From 2005, the number of studies examining the trajectory of undergraduate medical student 


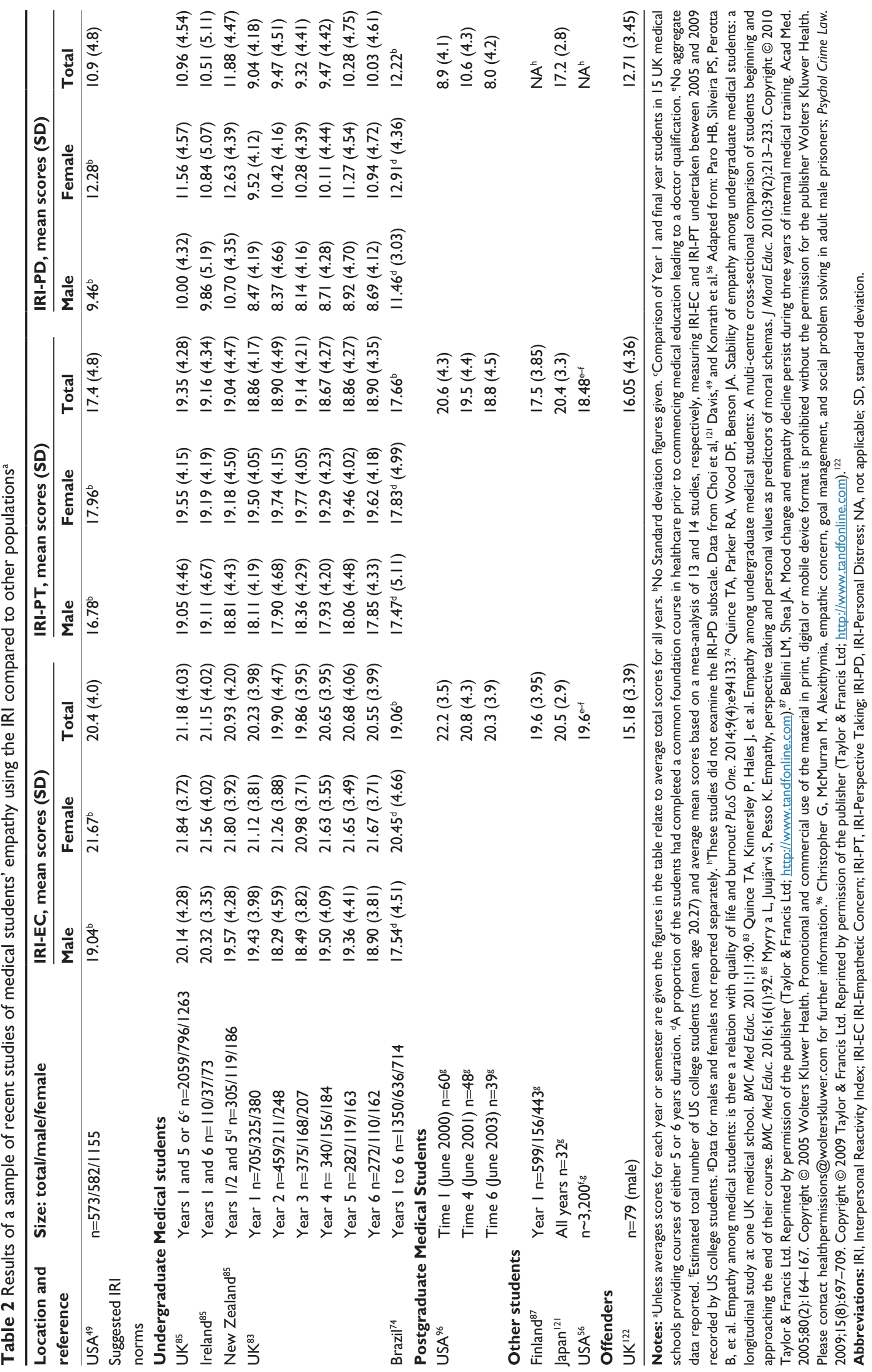


expanded, but results were mixed. Studies in India, Iran, the UK, the USA, and the Caribbean supported the view that empathy declined. ${ }^{46,47,63-65}$ Studies in Portugal, Korea, Japan, Iran, Bangladesh, the USA, Croatia, Brazil, and the UK reported either no change or an increase in empathy. ${ }^{66-75}$ Unsurprisingly, systematic reviews have also produced mixed results. A review by Neumann et al concluded that empathy declined, ${ }^{76}$ but a recent systematic review by Roff disputes this. ${ }^{77}$

Mixed results have also been reported about both the timing of the decline in empathy and the extent of sex differences in the trends displayed. Several studies suggest that empathy diminishes early in the undergraduate course, during phases devoted primarily to biomedical sciences. ${ }^{78,79}$ Other studies indicate that the decline occurs later, during more clinically oriented phases. ${ }^{80-82}$

The authors undertook a longitudinal study examining four cohorts of students entering one medical school between 2007 and $2010 .^{83}$ The school provides a 6 -year course, comprising a preclinical component devoted mainly to biomedical sciences with some clinical contact (years 1-3) and a clinical component (years 4-6). Students beginning each component were surveyed annually at the start of the academic year. Response rates ranged from $53 \%$ to $57 \%$ in the preclinical years and from $55 \%$ to $65 \%$ in the clinical years. Over 700 students in the preclinical component and $>400$ students in the clinical component participated. More than $60 \%$ in each component completed the survey more than once, and 66 students took part in all 6 years. Using the IRI, we found a statistically significant but small decline only in affective empathy (IRI-EC) and only among male students during the preclinical component. No changes in either affective or cognitive empathy were displayed by female students during either component of the course. ${ }^{83}$ In common with other studies, our work questioned the practical significance of the observed changes in empathy. This issue has been widely debated. ${ }^{84}$

We extended our longitudinal study to 18 medical schools: 16 in the UK, one in New Zealand, and one in Ireland. ${ }^{85} \mathrm{We}$ undertook a cross-sectional study which examined whether students nearing completion of their course recorded lower scores for empathy than those starting it. We used both the IRI and JSE-S. Response rates varied between schools and within schools between years, ranging from $7 \%$ to $78 \%$. Overall, 954 students nearing completion of their course did not record lower scores on any measure of empathy than 1,373 medical students beginning their course. No differences were found between male and female students in this respect, although female students recorded significantly higher empathy scores than males. ${ }^{85}$

The factors discussed as follows may explain some of the inconsistency in the results of these wide-ranging studies.

\section{Cross-sectional and single-institution studies}

Many studies of undergraduate medical students' empathy have been cross-sectional, comparing empathy in different cohorts. ${ }^{76,77}$ Differences in course content and structure may confound multi-institution studies, while in single-institution study, cohorts may differ. The difficulties of undertaking longitudinal work are reflected in the small number of such studies. Those that have been undertaken, such as the authors' own work, have usually been conducted in only one institution and have involved relatively few students. ${ }^{83}$ The single-institution focus and small number of participants make it difficult to generalize findings from small-scale cross-sectional and/or longitudinal studies. ${ }^{82,83}$

\section{Measurement}

Another problem is the tendency to use a single self-report instrument. This raises questions as to whether results using different instruments are truly comparable. In a recent study, the authors combined data from their cross-sectional study involving medical schools in the UK, New Zealand, and Ireland with data obtained by colleagues in Brazil and Portugal. The study examined the factorial structures and comparability of the JSE-S and this work suggested that the JSE-S and IRI are structurally different and measure only weakly related concepts. This may imply that results of studies using only one of the instruments may not be comparable with those using the other. It is likely that other instruments used to measure medical students' empathy also differ in respect of the precise constructs measured.

\section{Differences in different dimensions of empathy}

Although empathy is recognized to be multidimensional, few studies report the dimension of empathy in which the change occurs. The structure of the JSE-S would enable changes in the affective and cognitive dimensions of empathy to be observed; however, there is a tendency for studies using the JSE-S to report only the total score. In common with other studies using the IRI, the authors' single-institution study found a small change only in affective empathy. ${ }^{83}$

\section{Context}

Frequently studies examining medical students' empathy fail to report potentially important confounding variables, such as age and sex. (These factors are discussed later.) There is also a notable lack of details of course content and structure. We do not know whether problem-based or integrated courses help develop or preserve empathy. This lack is compounded by differences in ages and experience at admission. In the UK 
and much of Europe, most students enter medical training between the ages of 18 and 21. In North America, most of those entering medical training are at least 21.

\section{Summary}

There is no systematic evidence that undergraduate medical education diminishes empathy (nor is there evidence that it enhances empathy). This challenges the widely held view that medical education is inevitably associated with a decline in empathy. Nevertheless, the literature continues to offer a mixed picture, possibly related to limitations and differences in study design. Few studies are longitudinal and many focus on single institutions; details of study context, respondent sex, and different empathy components are often lacking; and different instruments appear to measure different constructs.

\section{What factors may influence the development of empathy? \\ Age}

Although there is some evidence that empathy increases with age, ${ }^{86}$ work comparing medical students who differ in age when they start their course is scarce. Attempts to widen access to medical education during the last decade have seen the development of accelerated graduate entry courses in the UK and elsewhere in Europe. Such courses typically last for 4 years as compared to 5/6 years for "standard entry" students. The authors' recent work with undergraduate medical students in the UK, Ireland, and New Zealand found that, at the beginning of their course, graduate entry course students recorded significantly higher mean scores for the JSE-S and IRI-PT, and significantly lower mean scores for IRI-PD than standard entry course students. No differences were found in respect of IRI-EC. Differences in the JSE-S, although statistically significant, were small in terms of effect size. Effect sizes of differences in IRI-PT and IRI-PD were larger. ${ }^{85}$ However, age alone may not explain this difference. Compared to standard entry, graduate entry students may be making a more conscious choice based on life experiences.

\section{Sex}

Empathy is widely considered to be normally distributed in the general population, but females have been found to record higher scores on self-report measures. ${ }^{24} \mathrm{~A}$ few studies have found no sex differences in the empathy scores reported by undergraduate medical students. ${ }^{67,70,79}$ In contrast, many studies in disparate cultural settings including Asia, Europe, and the Americas support the view that female medical students record higher empathy scores than their male counterparts. ${ }^{46,48,66,68,73-75,82,83}$
Unfortunately, few studies investigate and describe how the empathy recorded by male and female student differs over time. Where such details have been given, evidence suggests that female students show greater stability in respect of scores for "other directed" empathy than male students. ${ }^{82,83,85}$ However, because few studies have included self-directed personal distress (IRI-PD), the question remained as to whether female medical students record higher levels of personal distress and whether, as a result, they are more vulnerable.

\section{Culture}

Culture may also have an impact. Differences in scores for the JSE-S have often been observed in studies of medical students in different countries. ${ }^{46-48,65,66}$ Studies of students in Asian medical schools frequently report lower scores than studies undertaken in North American and European ones (Table 1). These differences have been ascribed to communication patterns which place less emphasis on nonverbal communication, the disposition of doctors preferred and expected by patients, the strongly science-oriented selection system among Asian medical schools, as well as differences in medical education per se. ${ }^{48,68}$ Whether these observed differences hold practical significance for medical practice in different cultural environments remain unclear. There has been little work examining the extent to which different cultural normative values influence empathy. A few studies have examined the relationship between values and empathy, but these have been conducted within the same broad cultural setting..$^{87,88}$

\section{Psychological well-being}

Specific psychiatric disorders have been found to be strongly associated with lower scores in certain dimensions of empathy ${ }^{89}$ Lower scores for cognitive empathy have been found to be associated with autism and offenders, whereas lower scores for affective empathy have been found to be associated with psychopathy. ${ }^{24,90}$

Associations have also been found between depression and perspective-taking abilities. ${ }^{91}$ When chronically depressed patients have been compared to controls, they have been found to have lower levels of perspective taking (IRI-PT) and higher levels of personal distress (IRI-PD) but no impairment of affective empathy (IRI-EC). ${ }^{92}$ Similar differences in empathy have been found among people suffering from bipolar disorder. ${ }^{93}$ However, the extent to which the relationships found between empathy and severe mental health disorders can be applied to medical students is questionable.

It is frequently argued that psychological distress is prevalent among medical students to a greater extent than among 
the general population, age-related peers, and nonmedical student peers. ${ }^{94-96}$ It is also suggested that medical students' psychological well-being deteriorates during medical education. ${ }^{94-96}$ Such views are not universally supported. ${ }^{97-99}$ Both the effect of psychological distress on medical students' empathy and the line of causality are uncertain..$^{97,100,101}$ Studies in North America report depression to be inversely related to empathy among women and burnout to be negatively correlated with empathy among all students. ${ }^{95}$

The authors' recent study involving 2,474 medical students in the UK, Ireland, and New Zealand found extremely weak negative correlations between depression scores as measured by HADS-D and empathy scores as measured by IRI-EC, IRI-PT, and JSE-S (Pearson correlation coefficients of, respectively, $-0.042,-0.078$, and -0.082 ). In contrast, stronger positive correlations were found between scores for both anxiety (HADS-A) and depression (HADS-D) and IRI-PD (personal distress) (Pearson correlation coefficients of, respectively, 0.312 and 0.220$).{ }^{85}$

The potential differential impact of each dimension of empathy may have important implications for medical education. For example, a study of medical students' judgments of pain-related symptoms found that students who recorded higher affective empathy scores (IRI-EC) were more likely to accept what patients say and rate symptoms as more severe than students recording lower affective empathy scores. ${ }^{101}$ By contrast, a small-scale Finnish study found that personal distress (IRI-PD) was negatively related to care-based moral development. ${ }^{87}$

\section{Aspects of the undergraduate course}

Course structure in terms of the extent and timing of clinical experience may influence the development and maintenance of empathy. Low levels of integration of clinical experience have been cited as a possible reason for cultural differences in empathy scores. ${ }^{68} \mathrm{~A}$ systematic review of the impact of early practical experience in medical training concluded that it fostered empathetic attitudes toward ill people. ${ }^{102}$ Studies of specific initiatives that involve extended, repeated, or more intensive exposure to clinical experience, even where that experience is effected through SPs, tend to support this view. ${ }^{40,103,104}$

The hidden curriculum may influence medical students' empathy, and yet, its impact remains under-researched. ${ }^{105}$ Many medical students report witnessing peers and supervisors making disparaging comments about, or references to, patients and colleagues, and reports of personal mistreatment by peers and faculty are not unusual. ${ }^{106,107}$ Medical students are often keenly aware of the empathy and communication skills displayed by clinical tutors and practicing clinicians that they observe when on placements. ${ }^{108,109}$

\section{Can empathy be taught?}

Empathy involves not only understanding the patient's situation and feelings but also being able to communicate that understanding. Communications skills are now taught as part of the core curricula of all the UK medical schools, and yet, 2 decades ago, such skills were rarely a formal part of the UK medical education. ${ }^{110}$ A review of intervention strategies aimed at enhancing empathy concluded that empathy was amenable positive change, with communication skills workshops addressing the behavioral aspects of empathy having the largest impact. ${ }^{111}$ However, there may still be a gap between what is taught in communication skills and how this is transferred to the clinical context. A recent study highlighted the need for greater collaboration between educators in the academic and clinical environments. ${ }^{112}$ Communication skills figure strongly in interventions aimed at enhancing empathy. In general, SPs involved in such interventions tend to report higher levels of satisfaction with encounters with the intervention group of students as compared to the control group of students. ${ }^{113,114}$

Reflective writing, ${ }^{115}$ drama or role play, ${ }^{116}$ and patient interviews ${ }^{117}$ are among methods used in interventions aimed at enhancing empathy. In a recent review, Batt-Rawden et al suggested that educational interventions could be successful in maintaining and enhancing undergraduate medical students' empathy. ${ }^{118}$ However, many interventions are evaluated over a relatively short time frame, and little is known about their longer term impact. Brazilian work suggests that there may well be a need to repeat such interventions over time. ${ }^{104}$

\section{Summary}

Many factors may influence the development and maintenance of empathy among undergraduate medical students. At a general level, these include age, sex, psychological well-being, and culture. But aspects of the undergraduate course such as the context and timing of clinical experience, the hidden curriculum, the communication skills training, and the other specific educational interventions may also play an important role. However, these factors have not been the central focus of studies of medical students' empathy hitherto.

\section{Future directions}

This review of research into medical students' empathy sought to address its measurement, its change during the undergraduate course, and the factors that may influence it. Three interrelated 
issues can be said to emerge for future research into undergraduate medical students' empathy (Figure 1).

\section{Definition of empathy}

Empathy is multidimensional, but, as noted, there is a lack of work in medical education examining its different dimensions, their impact, and what influences them in a clinical context. Studies of medical students' empathy frequently do not define or report results for different dimensions of empathy, yet the widely used JSE-S and IRI provide measures of affective and cognitive empathy. If such reporting were done in relation to educational interventions aimed at enhancing empathy, then a clearer picture would emerge as to whether empathy is amenable to being taught.

Possible negative impacts of empathy in terms of overidentification with the suffering of patients are unknown. This may help in understanding resilience among doctors, a key issue in modern medical practice. There is also a need to examine the impact of lack of empathy, incorporating moral and behavioral dimensions. This work would be strengthened by incorporating work from other disciplines, including the influence of normative values on attitudes, behavior, and decision making.

\section{Measurement of empathy}

Single, self-report instruments have the advantage of utility across large populations. The need for greater granularity in describing the dimension of empathy measured has already been suggested. However, there remain questions as to the measurement fidelity and comparability of self-report instruments. The development of the JSE-S and its widespread application have provided a basis for comparability. However, while the JSE-S is context specific, it remains unclear

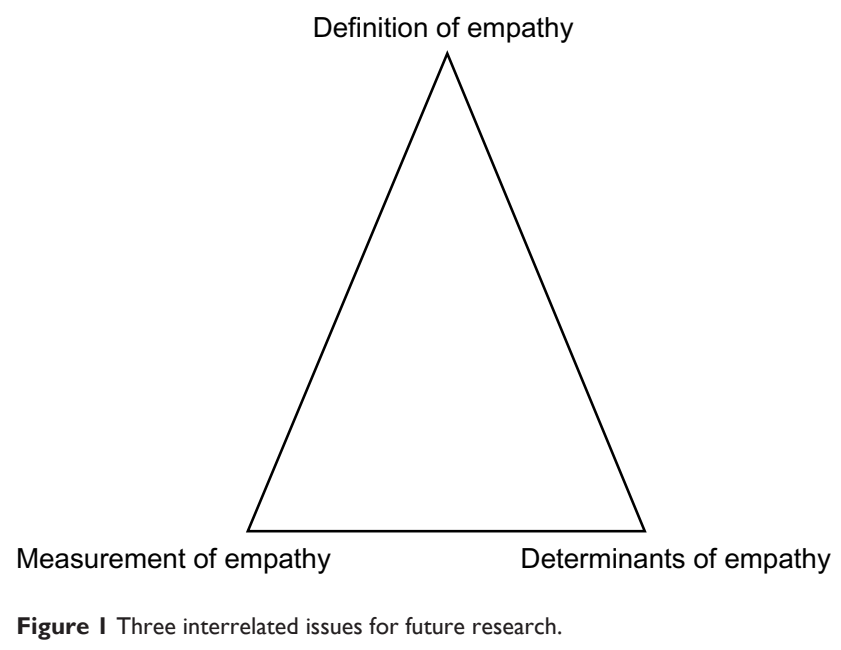

to what extent it measures a socially desirable view of the ideal doctor.

There is also the question about whether self-report instruments are relevant for the real-world clinical practice, as experienced by patients. The fidelity of self-report instruments could be enhanced by triangulation, such as using more than one instrument, and using them in conjunction with direct observation of empathetic practice, and simulated or real patients' evaluations. Many instruments have been developed to assess patients' experiences, yet few studies of medical students' empathy incorporate these. ${ }^{119}$

There is an overwhelming need for more qualitative work. We know little of what students regard as empathetic practice, and for example, how this relates to their normative values. More importantly, we know little about what students observe as empathetic practice and the context of that observation. Such work would highlight not only opportunities for enhancing empathy but also the impact of role models and the hidden curriculum. Qualitative work focusing on critical incidents, such as a student's first experience of a patient's death, would also help elucidate influences on context-specific empathy. Although difficult to undertake, both quantitative and qualitative longitudinal work could also help pinpoint the timing of nature of experiences, which influence changes in empathy.

\section{Determinants of empathy}

Current evidence does not support the contention that undergraduate medical education universally diminishes empathy. In addition, some of the changes observed may be of questionable practical significance. Nevertheless, there is a need to focus on developing a better understanding of what influences empathy and how empathy can be developed and enhanced.

Studies suggest that age, sex, and culture all influence empathy. There is a need for more studies comparing entrants to medical education who differ in age and relevant life experience. Despite evidence that female medical students record higher scores on self-report instruments measuring empathy, few studies report sex differences overtime. The impact of medical students' psychological well-being on the different dimensions of empathy has also received little attention. Similarly, cross-cultural studies that take account of prevailing cultural norms and values and differences in medical practices and patients' expectations of doctors are also rare.

A notable need is for more understanding of the impact of differences in course content and structure. There is a need for 
studies to describe, in more detail, aspects such as the timing, context, and nature of clinical experience. Such description needs to go beyond simplistic labels such as "integrated" or "problem-based". However, achieving realistic sample sizes to investigate these relationships may remain challenging. Although short-term evaluations appear to support the view that educational interventions can enhance empathy, further investigation is needed into the longer term impacts of such interventions.

\section{Conclusion}

Existing work has gone a long way to describe the nature of empathy among medical students and factors that may influence it. Nevertheless, there remains a need for greater clarity of definition of empathy; for development of meaningful measures, relating to different components of empathy, and which are relevant to patients' experience; and for studies with the methodological rigor to clarify those determinants of empathy which are amenable to influence by medical education. Greater specificity of context and the incorporation of work from other disciplines may facilitate this.

Investigation of the level, trajectory, and determinants of empathy in medical students during their education will remain difficult. Nevertheless, as a key component of good medical care, the underlying concept has perhaps never been more important.

\section{Disclosure}

The authors report no conflicts of interest in this work.

\section{References}

1. Francis R. Report of the Mid Staffordshire NHS Foundation Trust Public Inquiry: executive summary. http://webarchive.nationalarchives.gov. uk/20150407084003/http://www.midstaffspublicinquiry.com/report. Accessed March 10, 2015.

2. Thom DH. Physician behaviors that predict patient trust. J Fam Pract. 2001;50(4):323-328.

3. Krupat E, Bell RA, Kravitz RL, Thom D, Azari R. When physicians and patients think alike: patient-centred beliefs and their impact on satisfaction and trust. J Fam Pract. 2001;50(12):1057-1062.

4. Reiss HT, Clark MS, Pereira Gray DJ, et al. Measuring the responsiveness in the therapeutic relationship: a patient perspective. Basic Appl Soc Psychol. 2008;30(4):339-348.

5. Kim SS, Kaplowitz S, Johnston MV. The effects of physician empathy on patient satisfaction and compliance. Eval Health Prof. 2004;27(3): 237-251.

6. Derksen F, Bensing J, Lagro-Janssen A. Effectiveness of empathy in general practice: a systematic review. Br J Gen Pract. 2013;63(606): e76-e84.

7. Zachariae R, Pedersen CG, Jensen AB, et al. Association of perceived physician communication style with patient satisfaction, distress, cancer-related self-efficacy, and perceived control over the disease. Br J Cancer. 2003;88(5):658-665.

8. Bandura A. Self-efficacy-The Exercise of Control. New York: Freeman and Company; 1997.
9. Vermeire E, Hearnshaw H, Van Royen P, Denekens J. Patient adherence to treatment: three decades of research. A comprehensive review. J Clin Pharm Ther. 2001;26(5):331-342.

10. Del Canale S, Louis DZ, Maio V, et al. The relationship between physician empathy and disease complications: an empirical study of primary care physicians and their diabetic patients in Parma, Italy. Acad Med. 2012;87(9):1243-1249.

11. Hojat M, Louis DZ, Markham FW, Wender R, Rabinowitz C, Gonnella JS. Physicians' empathy and clinical outcomes for diabetic patients. Acad Med. 2011;86(3):359-364.

12. Rakel D, Barrett B, Zhang Z, et al. Perception of empathy in the therapeutic encounter: effects on the common cold. Patient Educ Couns. 2011;85(3):390-397.

13. Neumann M, Wirtz M, Bollschweiler E, et al. Determinants and patient-reported long-term outcomes of physician empathy in oncology: a structural equation modelling approach. Patient Educ Couns. 2007;69(1-3):63-75.

14. Price S, Mercer SW, MacPherson H. Practitioner empathy, patient enablement and health outcomes: a prospective study of acupuncture patients. Patient Educ Couns. 2006;63(1-2):239-245.

15. Gleichgerrcht E, Decety J. The relationship between different facets of empathy, pain perception and compassion fatigue among physicians. Front Behav Neurosci. 2014;8:243.

16. Larson EB, Yao X. Clinical empathy as emotional labor in the patientphysician relationship. JAMA. 2005;293(9):1100-1106.

17. Coulehan JL, Platt FW, Egener B, et al. "Let me see if I have this right...": words that help build empathy. Ann Intern Med. 2001;135(3):221-227.

18. Beckman HB, Frankel RM. Training practitioners to communicate effectively in cancer care: it is the relationship that counts. Patient Educ Couns. 2003;50(1):85-89.

19. Levinson W, Gorawara-Bhat R, Lamb J. A study of patient clues and physician responses in primary care and surgical settings. JAMA. 2000;284(8):1021-1027.

20. Skinner C, Spurgeon P. Valuing empathy and emotional intelligence in health leadership: a study of empathy, leadership behavior and outcome effectiveness. Health Serv Manage Res. 2005;18(1):1-12.

21. Neumann M, Bensing J, Mercer S, et al. Analysing the "nature" and "specific effectiveness" of clinical empathy: a theoretical overview and contribution towards a theory based research agenda. Patient Educ Couns. 2009;74(3):339-346.

22. Pedersen R. Empirical research on empathy in medicine-a critical review. Patient Educ Couns. 2009;76(3):307-322.

23. Hemmerdinger J, Stoddart SD, Lilford RJ. A systematic review of tests of empathy in medicine. BMC Med Educ. 2007;7:24.

24. Baron-Cohen S. Zero Degrees of Empathy. London, UK: Penguin; 2011.

25. Posick C, Rocque M, Rafter N. More than a feeling: integrating empathy into the study of lawmaking, lawbreaking, and reactions to lawbreaking. Int J Offender Ther Comp Criminol. 2014;58(1):5-26.

26. Halpern J. From idealized clinical empathy to empathetic communication in medical care. Med Health Care Philos. 2014;17(2):301-311.

27. Mercer SW, Reynolds WJ. Empathy and the quality of care. Br J Gen Pract. 2002:52 (Suppl):S9-S13.

28. Lamm C, Batson CD, Decety J. The neural substrate of human empathy: effects of perspective taking and cognitive appraisal. J Cogn Neurosci. 2007;19(1):42-58.

29. Wang Q, Zhang Z, Dong F, et al. Anterior insula GABA levels correlate with emotional aspects of empathy: a proton magnetic resonance spectroscopy study. PLoS One. 2014;9(11):e113845.

30. van Langen MAM, Wissink IB, van Vugt ES, Van der Stouwe T, Stams GJJM. The relation between empathy and offending: a meta-analysis. Aggress Violent Behav. 2014;19(2):179-189.

31. van Noorden TH, Haselager GJ, Cillessen AH, Bukowski WM. Empathy and involvement in bullying in children and adolescents: a systematic review. J Youth Adolesc. 2014;44(3):637-657.

32. Barth J, Lannen P. Efficacy of communication skills training courses in oncology: a systematic review and meta-analysis. Ann Oncol. 2011;22(5):1030-1040. 
33. Jackson PL, Meltzoff AN, Decety J. How do we perceive the pain of others? A window into the neural processes involved in empathy. Neuroimage. 2005;24(3):771-779.

34. Benson J, Quince T, Hibble A, Fanshawe T, Emery J. The impact on patients of expanded, general practice based, student teaching: observational and qualitative study. BMJ. 2005;331(7508):89.

35. Silvester J, Patterson F, Koczwara A, Ferguson E. "Trust me ....” Psychological and behavioral predictors of perceived physician empathy. J Appl Psychol. 2007;92(2):519-527.

36. O’Connor K, King R, Malone KM, Guerandel A. Clinical examiners, simulated patients and student self-assessed empathy in medical students during a psychiatry Objective Structured Clinical Examination. Acad Psychiatry. 2014;38(4):451-457.

37. Berg K, Blatt B, Lopreiato J, et al. Standardised patients' assessment of medical student empathy: ethnicity and gender in a multi-institutional study. Acad Med. 2015;90(1):105-111.

38. Berg K, Majden JF, Berg D, Veloski J, Hojat M. Medical students selfreported empathy and simulated patients'assessment of student empathy: an analysis by gender and ethnicity. Acad Med. 2011;86(8):984-988.

39. Schweller M, Costa FO, Antônio MA, Amaral EM, De CarvalhoFilho MA. The impact of simulated medical consultations on empathy levels of students at one medical school. Acad Med. 2014;89(4):632-637.

40. Johnston JL, Lundy G, McCullough M, Gormley GJ. The view from over there: reframing the OSCE through the experience of standardised patient rates. Med Educ. 2013;47(9):899-909.

41. Ogle J, Bushnell JA, Caputi A. Empathy is related to clinical competence in medical care. Med Educ. 2013;47(8):824-831.

42. Lee J, Zaki J, Harvey PO, Ochsner K, Green MF. Schizophrenia patients are impaired in empathetic accuracy. Psychol Med. 2011;41(11):2297-2304.

43. Hojat M. Empathy in Patient Care: Antecedents, Development, Measurement, and Outcomes. Philadelphia: Springer; 2007 (Chapter 7).

44. Fields SK, Mahan P, Tillman P, Harris J, Maxwell K, Hojat M. Measuring empathy in healthcare profession students using the Jefferson Scale of Physician Empathy: healthcare provider - student version. J Interprof Care. 2011;25(4):287-293.

45. Ward J, Schaal M, Sullivan J, et al. Reliability and validity of the Jefferson Scales of Physician Empathy in undergraduate nursing students. J Nurs Meas. 2009;17(1):73-88.

46. Shashikumar R, Chaudhary R, Ryali VS, et al. Cross sectional assessment of empathy among undergraduates from a medical college. Med J Armed Forces India. 2014;70(2):179-185.

47. Shariat SV, Habibi M. Empathy in Iranian medical students: measurement model of the Jefferson Scale of Empathy. Med Teach. 2013; 35(1):e913-e918.

48. Park KH, Roh H, Sun DH, Hojat M. Empathy in Korean medical students: findings from a nationwide survey. Med Teach. 2015;37(10) 943-948

49. Davis MH. A multidimensional approach to individual differences in empathy. JSAS Catalog Selected Documents Psychol. 1980;10:85.

50. Davis MH. Measuring individual differences in empathy: evidence for a multidimensional approach. J Pers Soc Psychol. 1983;44(1) 113-126.

51. Lehmann A, Bahcesular K, Brockmann EM, et al. Subjective experience of emotions and emotional empathy in paranoid schizophrenia. Psychiatry Res. 2014;220(3):825-833.

52. Narme P, Mouras H, Roussel M, Duru C, Krystowiak P, Godefroy O. Emotional and cognitive social processes are impaired in Parkinson's disease and are related to behavioral disorders. Neuropsychology. 2013;27(2):182-192.

53. Schaffer M, Clark S, Jeglic EL. The role of empathy and parent- ing style in the development of antisocial behaviors. Crime Delinq. 2009;55(4):586-599.

54. Eberly-Lewis MB, Coetzee TM. Dimensionality in adolescent prosocial tendencies: individual differences in serving others versus serving the self. Pers Individ Dif. 2015;82:1-6.
55. Parton F, Day A. Empathy, intimacy, loneliness and locus of control in child sex offenders: a comparison between familial and non-familial child sexual offenders. J Child Sex Abus. 2002;11(2):41-57.

56. Konrath SH, O'Brien EH, Hsing C. Changes in dispositional empathy in American college students over time: a meta-analysis. Pers Soc Psychol Rev. 2011;15(2):180-198.

57. Costa P, Carvalho-Filho M, Schweller M. et al. Measuring medical students' empathy: exploring the underlying constructs of and associations between, two widely used self-report instruments in five countries. Acad Med. In press 2016.

58. Hojat M, Gonnella JS. Eleven years of data on the Jefferson Scale of Empathy-Medical Student Version JSE-S: proxy norm data and tentative cut-off scores. Med Princ Pract. 2015;24(4):344-350.

59. Bock EM, Hosser D. Empathy as a predictor of recidivism among young adult offenders. Psychol Crime Law. 2014;20(2):101-115.

60. Haidet P, Daines JE, Paterniti DA, et al. Medical student attitudes towards the doctor-patient relationship. Med Educ. 2002;36(6): $568-574$.

61. Hojat M, Mangione S, Nasca TJ, et al. An empirical study of decline in empathy in medical school. Med Educ. 2004;38(9):934-941.

62. Woloschuk P, Harasym PH, Temple W. Attitude change during medical school: a cohort study. Med Educ. 2004;38(5):522-534.

63. Austin EJ, Evans P, Magnus B, O’Hanlon K. A preliminary study of empathy, emotional intelligence and examination performance in MBChB students. Med Educ. 2007;41(7):684-689.

64. Chen D, Lew R, Hershman W, Orlander J. A cross-sectional measurement of medical student empathy. $J$ Gen Intern Med. 2007;22(10):1434-1438.

65. Youssef FF, Nunes P, Sa B, Williams S. An exploration of changes in cognitive and emotional empathy among medical students in the Caribbean. Int J Med Educ. 2014;5:185-192.

66. Magalhães E, Salgueira AP, Costa P, Costa MJ. Empathy in senior year and first year medical students: a cross-sectional study. BMC Med Educ. 2011;11:52.

67. Roh MS, Hahm BJ, Lee DH, et al. Evaluation of empathy among Korean medical students: a cross-sectional study using the Korean version of the Jefferson Scale of Physician Empathy. Teach Learn Med. 2010;22(3):167-171.

68. Kakaoka HU, Koide N, Ochi K, Hojat M, Gonnella JS. Measurement of empathy among Japanese medical students: psychometrics and score differences by gender and level of medical education. Acad Med. 2009;84(9):1192-1197.

69. Lee BK, Bahn GH, Lee WH, Park JH, Yoon TY, Baek SB. The relationship between empathy medical education system, grades and personality in medical college and medical school. Korean J Med Educ. 2009;21(2):117-124.

70. Rahimi-Madiseh M, Tavakol M, Dennick R, Nasiri J. Empathy in Iranian medical students: a preliminary psychometric analysis and differences by gender and year of medical school. Med Teach 2010;32(11):e471-e478.

71. Mostafa A, Hogue R, Mostafa M, Rang MM, Mostafa F. Empathy in undergraduate medical students of Bangladesh: psychometrics analysis and differences by gender, academic year and speciality preferences. ISRN Psychiatry. 2014;2014:375-439.

72. Toto RL, Man L, Blatt B, Simmens SJ, Greenberg L. Do empathy, perspective-taking, sense of power and personality differ across undergraduate education and are they inter-related? Adv Health Sci Educ Theory Pract. 2015;20(1):23-31.

73. Bratek A, Bulska W, Bonk M, Seweryn M, Krysta K. Empathy among physicians, medical students and candidates. Psychiatr Danub. 2015;27 (Suppl 1):S48-S52.

74. Paro HB, Silveira PS, Perotta B, et al. Empathy among medical students: is there a relation with quality of life and burnout? PLoS One. 2014;9(4):e94133.

75. Tavakol S, Dennick R, Tavakol M. Empathy in UK medical students: differences by gender, medical year and specialty interest. Educ Prim Care. 2011;22(5):297-303. 
76. Neumann M, Edlehäuser F, Tauschel D, et al. Empathy decline and its reasons: a systematic review of studies with medical students and residents. Acad Med. 2011;86(8):996-1009.

77. Roff S. Reconsidering the "decline" of medical student empathy as reported in studies using the Jefferson Scale of Physician Empathy- Student version (JSPE-S). Med Teach. 2015:37(8): $783-786$.

78. Newton BW, Barber L, Clardy J, Cleveland E, O'Sullivan P. Is there hardening of the heart during medical school? Acad Med. 2008;83(3):244-249.

79. Williams B, Sadasivan S, Kadirvelu A. Malaysian medical students selfreport empathy: a cross-sectional comparative study. Med J Malaysia. 2015;70(2):76-80.

80. Hojat M, Vergare MJ, Maxwell K, et al. The devil is in the third year: a longitudinal study of erosion of empathy in medical school. Acad Med. 2009;84(9):1182-1191.

81. Khademalhosseini M, Khademalhosseini Z, Mahmoodian F. Comparison of empathy among medical students in both basic sciences and clinical levels. J Adv Med Educ Prof. 2014;2(2):88-91.

82. Chen DC, Kirshenbaum DS, Yan J, Kirshenbaum E, Aseltine RH. Characterizing changes in student empathy throughout medical school. Med Teach. 2012;34(4):305-311.

83. Quince TA, Parker RA, Wood DF, Benson JA. Stability of empathy among undergraduate medical students: a longitudinal study at one UK medical school. BMC Med Educ. 2011;11:90.

84. Colliver JA, Conlee MJ, Verhulst SJ, Dorsey JK. Reports of the decline of empathy during medical education are greatly exaggerated: a reexamination of the research. Acad Med. 2010;85(4):588-593.

85. Quince TA, Kinnersley P, Hales J, et al. Empathy among undergraduate medical students: A multi-centre cross-sectional comparison of students beginning and approaching the end of their course. BMC Med Educ. 2016;16(1):92.

86. Ze O, Thomas P, Suchan B. Cognitive and affective empathy in younger and older individuals. Aging Ment Health. 2014;18(7):929-935.

87. Myyry L, Juujärvi S, Pesso K. Empathy, perspective taking and personal values as predictors of moral schemas. J Moral Educ. 2010;39(2):213-233.

88. Coulter ID, Wilkes M, Der-Martirosian C. Altruism revisited: a comparison of medical, law and business students' altruistic attitudes. Med Educ. 2007;41(4):341-345.

89. Blair RJ. Responding to the emotions of others: dissociating forms of empathy through the study of typical and psychiatric populations. Conscious Cogn. 2005;14(4):698-718.

90. van Langen MAM, Wissink IB, van Vugt ES, Van der Stouwe T, Stams GJJM. The relationship between empathy and offending: a meta analysis. Aggress Violent Behav. 2014;19(2):179-189.

91. Wilbertz, G, Brakemeier EL, Zobel I, Härter M, Schramm E. Exploring the preoperational features in chronic depression. J Affect Disord. 2010;124(3):262-269.

92. Cusi AM, MacQueen GM, Spreng RN, McKinnon MC. Altered empathetic responding in major depressive disorder: relation to symptom severity, illness burden and psychosocial outcome. Psychiatry Res. 2011;188(2):231-236.

93. Cusi A, MacQueen GM, McKinnon MC. Altered self-report empathetic responding in patients with bi-polar disorder. Psychiatry Res. 2010;178(2):354-358.

94. Hope V, Henderson M. Medical student depression, anxiety and distress outside North America: a systematic review. Med Educ. 2014;48(10):963-979.

95. Dyrbye LN, Thomas MR, Shanafelt TD. A systematic review of depres- sion, anxiety and other indicators of psychological distress among US and Canadian medical students. Acad Med. 2006;81(4): 354-373.

96. Bellini LM, Shea JA. Mood change and empathy decline persist during three years of internal medical training. Acad Med. 2005;80(2):164-167.
97. Quince TA, Wood DF, Parker RA, Benson J. Prevalence and persistence of depression among undergraduate medical students: a longitudinal study at one UK medical school. BMJ Open. 2012;2(4):e001519.

98. Brazeau CM, Shanafelt T, Durning SJ, et al. Distress among matriculating medical students relative to the general population. Acad Med. 2014;89(11):1520-1525.

99. Dahlin M, Nilsson C, Stotzer E, Runeson B. Mental distress, alcohol use and help-seeking among medical and business students: a crosssectional comparative study. BMC Med Educ. 2011;11:92.

100. Bassols AM, Okabayashi LS, Silva AB, et al. First and last year medical students: is there a differences in the prevalence and intensity of anxiety and depressive symptoms? Rev Bras Psiquiats. 2014;36(3):233-240.

101. Chibnall JT, Tait RC, Jovel A. Accountability and empathy effects on medical students' clinical judgments in a disability determination context for low back pain. J Pain. 2014;15(9):915-924.

102. Littlewood S, Ypinazar V, Margolis SA, Scherpbier A, Spencer J, Dornan T. Early practical experience and the social responsiveness of clinical education: systematic review. BMJ. 2005;331(7513): 387-391.

103. Krupat E, Pelletier S, Alexander EK, Hirsh D, Ogur B, Schwartzstein R. Can changes in the principal clinical year prevent the erosion of students' patient-centred beliefs? Acad Med. 2009;84(5):582-586.

104. Schweller M, de Jorge B, Santos TM, Grangeia TdeAG, de CarvalhoFilho, MA. Do it again! Medical students achieve higher empathy levels when exposed a simulated training with standardised patients more than once. Poster presented at: AMEE Conference; 2015; Glasgow.

105. Hafferty FW. Beyond curriculum reform: confronting medicine's hidden curriculum. Acad Med. 1998;73(4):403-407.

106. West CP, Shanafelt TD. The influence of personal and environmental factors on professionalism in medical education. BMC Med Educ. 2007;7:29

107. Caldicott CV, Faber-Langendoen K. Deception, discrimination and fear of reprisal: lessons in ethics from third year medical students. Acad Med. 2005;80(9):866-873.

108. Burgess A, Goulston K, Oates K. Role modelling of clinical tutors a focus group study among medical students. BMC Med Educ. 2015;15:17.

109. Karnieli-Miller O, Vu TR, Frankel RM, et al. Which experiences in the hidden curriculum teach medical students about professionalism? Acad Med. 2011;86(3):369-377.

110. Brown J. How clinical communication has become a core part of medical education in the UK. Med Educ. 2008;42(3):271-278.

111. Stepien KA, Baernstein A. Educating for empathy. J Gen Intern Med. 2006;21(5):524-530.

112. Brown J. Transferring clinical communication skills from the classroom to the clinical environment: perceptions of a group of medical students in the United Kingdom. Acad Med. 2010;85(6):1052-1059.

113. Blatt B, Le Lacheur SF, Galinsky AD, Simmens SJ, Greenberg L. Does perspective taking increase patient satisfaction in medical encounters? Acad Med. 2010;85(9):1445-1452.

114. Fernández-Olano C, Montoya-Fernández J, Salinas-Sánchez AS. Impact of clinical interview training on empathy level of medical students and medical residents. Med Teach. 2008;30(3):322-324.

115. DasGupta S, Charon R. Personal illness narratives: using reflective writing to teach empathy. Acad Med. 2004;79(4):351-356.

116. Lim BT, Moriarty H, Huthwaite M. "Being in role": a teaching innovation to enhance empathetic communication skills in medical students. Med Teach. 2011;33(12):e663-e669.

117. Mullen K, Nicolson M, Cotton P. Improving medical students' attitudes towards the chronic sick. BMC Med Educ. 2010;10:84.

118. Batt-Rawden S, Chisolm MS, Anton B, Flickinger TE. Teaching empathy to medical students: an updated systematic review. Acad Med. 2013;88(8):1171-1177.

119. de Silva D. No. 18. Measuring Patient Experience. London, UK: The Health Foundation; 2013. 
120. Hegazi I, Wilson I. Maintaining empathy in medical school: it is possible. Med Teach. 2013;35(12):1002-1008.

121. Choi D, Nishimura T, Motoi M, EgashiraY, Matsumoto R, Watanuki S. Effect of empathy trait on attention to various facial expressions: evidence from N170 and late positive potential (LPP). J Physiol Anthropol. 2014;33(1):18.
122. Christopher G, McMurran M. Alexithymia, empathic concern, goal management, and social problem solving in adult male prisoners. Psychol Crime Law. 2009;15(8):697-709.

\section{Publish your work in this journal}

Advances in Medical Education and Practice is an international, peerreviewed, open access journal that aims to present and publish research on Medical Education covering medical, dental, nursing and allied health care professional education. The journal covers undergraduate education, postgraduate training and continuing medical education including emerging trends and innovative models linking education, research, and health care services. The manuscript management system is completely online and includes a very quick and fair peer-review system. Visit http://www.dovepress.com/testimonials.php to read real quotes from published authors.

Submit your manuscript here: http://www.dovepress.com/advances-in-medical-education-and-practice-journal 